\title{
Erratum to: High-frequency aflibercept injections in persistent neovascular age-related macular degeneration
}

\author{
Ilkay Kilic Muftuoglu ${ }^{1,2} \cdot$ Frank F. Tsai $^{1,3} \cdot$ Raouf Gaber $^{1} \cdot$ Mostafa Alam $^{1,5}$. $^{1}$ \\ Amit Meshi ${ }^{1}$ - William R. Freeman ${ }^{1,4}$
}

Published online: 19 May 2017

(C) Springer-Verlag Berlin Heidelberg 2017

Erratum to: Graefes Arch Clin Exp Ophthalmol (2017)

255:709-717

DOI 10.1007/s00417-016-3547-z

Reason: Mostafa Alam, MD is affiliated with both the Department of Ophthalmology, Jacobs Retina Center at the Shiley Eye Institute, University of California San Diego, La Jolla, CA and the Department of Ophthalmology, Tanta University, Tanta, Egypt”.

Corrected version: Ilkay Kilic Muftuoglu1,2 \& Frank F. Tsai1,3 \& Raouf Gaber1 \& Mostafa Alam1,5 \& Amit Meshi1 \& William R. Freeman1,4.

5. Department of Ophthalmology, Tanta University, Tanta, Egypt.

The online version of the original article can be found at http://dx.doi.org/ $10.1007 / \mathrm{s} 00417-016-3547-\mathrm{z}$

William R. Freeman

freeman@eyecenter.ucsd.edu

1 Department of Ophthalmology, Jacobs Retina Center at the Shiley Eye Institute, University of California San Diego, La Jolla, CA, USA

2 Department of Ophthalmology, Istanbul Training and Research Hospital, Istanbul, Turkey

3 Present address: Sharp Rees-Stealy Medical Group Division of Ophthalmology, San Diego, CA, USA

4 Jacobs Retina Center at the Shiley Eye Institute, University of California San Diego, 94093 Campus Point Drive, La Jolla, CA 92037, USA

5 Department of Ophthalmology, Tanta University, Tanta, Egypt 